\title{
Sesquiterpene Lactones of Iranian Compositae Family (Astraceae); Their Chemical Constituents and Anti-plasmodial Properties of Tehranolide (A.Review)
}

\author{
ABDOLHOSSEIN RUSTAIYAN ${ }^{1 *}$, AFSANEH FARIDCHEHR ${ }^{2}$ and MAHDI BAKHTIYAR ${ }^{3}$ \\ 1,2Department of Chemistry, Faculty of Basic Sciences. Science and Research Branch \\ Islamic Azad University, Tehran, Iran \\ ${ }^{3}$ Shahdara Caspian, Pharmaceutical and Cosmetic Company, Tehran, Iran. \\ ${ }^{*}$ Corresponding author E-mail: arustaiyan @yahoo.it \\ http://dx.doi.org/10.13005/ojc/330506
}

(Received: May 06, 2017; Accepted: June 30, 2017)

\section{ABSTRACT}

\begin{abstract}
Sesquiterpene lactones constitute a large and diverse group of biologically active plant chemical that have been identified in the several plant families. The pharmacological properties of interest involving the sesquiterpene lactones are their antibacterial, antifungal and anti-plusmodial activities. Indeed, assessing the biological activities of the sesquiterpene lactones found in plants and their essential oil is of great medicinal importance because they could potentially be utilized as therapeutic agents for the treatment of such infections.
\end{abstract}

Keywords: Iranian Compositae Family (Asteraceae), Germacranolides, Eudesmanolides, Guaianolides, Elemanolides, Constituents and Biological Activities.

\section{INTRODUCTION}

Sesquiterpene lactones are one of the most prevalent and biologically significant classes of secondary metabolite present, and as such have subject to a number of studies.

Sesquiterpene lactones are a group of secondary metabolites found across the plant kingdom comprising a large group of over 5500 known compounds'being most prevalent in the family Asteracea. Sesquiterpenoids are typically located in laticifers, which are specialized secretary cells in most of the Asteraceae, but can also be found within the vacuoles of other cell types in the plant, specifically when produced in response to biotic stresses. They are one of the main constituents of latex in latex producing plants, and they are frequently potent antimicrobial agents as well as antifeedants to chewing insects and birds. They also have a range of other effects such as allelopathy, stimulation of germination in the parasitic plant Orobanche ${ }^{2}$.

In fact, The Iranian compositae (Astracea) family has yielded a considerable amount of new, interesting sesquiterpene lactones. 


\section{Chemical constituents}

Onopordon leptolepis DC.

Onopordon leptolepis DC. Growing in Iran has not been investigated before. The aerial parts also contain Onopordopicrin 1, and two new germacranolides (2 and 3 ), closely related to $2^{3}$.
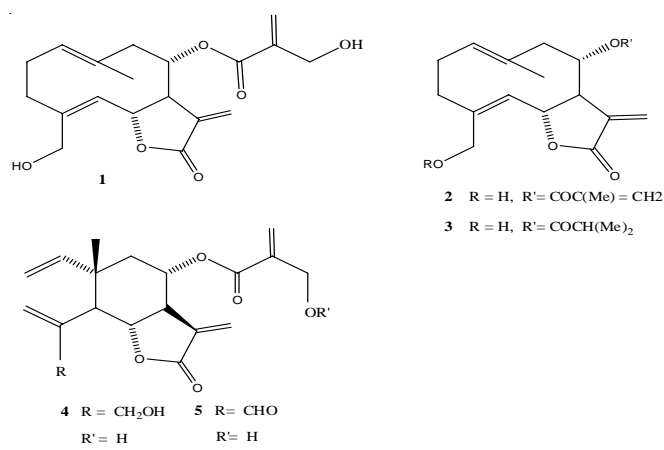

$3 \mathrm{R}=\mathrm{H}, \mathrm{R}^{\prime}=\mathrm{COCH}(\mathrm{Me})_{2}$

Fig. 1. Chemical structures of Sesquiterpene lactones from Onopordon leptolepis DC.1-5.

The investigation of the polar fractions of the aerial parts of Onopordon leptolepis afforded two new elemanolides, their structures being elucidated by spectroscopic methods and by partial synthesis starting with Onopordopicrin ${ }^{4}$.

A Guaianolide from Jurinea carduiformis Boiss.

The aerial parts of $J$. carduiformis. afforded, in addition to Repin $(6)^{5}$ and Janerin $(7)^{7}$, small amounts of a further lactone 8 , the structure of which was deduced from the $\mathrm{H}^{1}$-NMR data especially by comparison with the spectra of 6 and $7^{7}$.

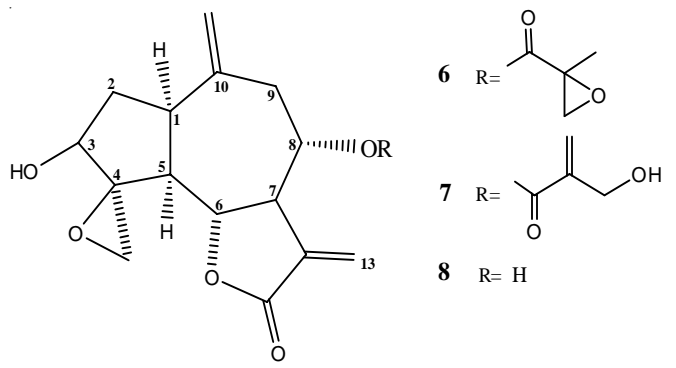

Fig. 2.Chemical structures of Sesquiterpene lactones from Jurinea carduiformis Boiss.6-8

Guaianolides from Acroptilon repens DC.

The aerial part of $A$. repens (Centaurea picris)

DC. has been investigated several times. ${ }^{8}$. Two guaianolides were isolated, chlorohyssopifolin $\mathrm{C}(9)^{8}$ and Repin (10) ${ }^{9} . A$ reinvestigation afforded, in addition to these lactones, Janerin $(11)^{7}$, chlorohyssopifolin A $(12)^{10}$ and two other lactones, which are the closely related guaianolides 13 and 15. The structures followed from the $\mathrm{H}^{1}$-NMR data, especially if compared with those of 10-12. Acetylation of 13 gave the diacetate14; its $\mathrm{H}^{1}-\mathrm{NMR}$ data showed that the stereochemistry at $\mathrm{C}-5$, through $\mathrm{C}-8$ was the same as that of 9-12, which the presence of a C-4 methylene group was indicated by two broadened signals at $\delta 5.68$ and $5.43 \mathrm{ppm}$ in the spectra of $13^{11}$.
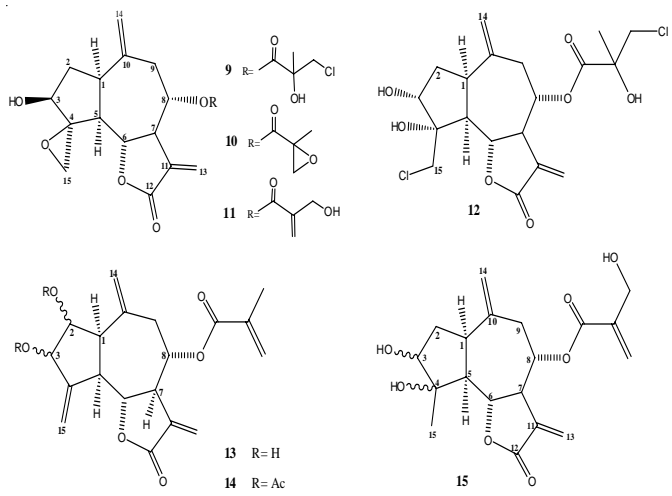

Fig. 3.Chemical structures of Sesquiterpene lactones from Acroptilon repens DC.9-15

\section{Guaianolides from Centaurea behen $\mathrm{L}$.}

Centaurea behen L. native in Iran had not been investigated chemically. The aerial parts of this plant afforded several sesquiterpene lactones, the guaianolides cynaropicrin $(16)^{12}$, arguerin B $(18)^{13}$, desacylcynaropicrin $(19)^{14}$, grosshemin $(21)^{15}$ and minor amounts of the ketone 23 , which is closely related to solstitialin $A$, the absolute configuration of which had been established ${ }^{16}$. Structure 23 could only be isolated as its diacetate 24 , which still was mixed with the acetate of 21 . The latter, however, could be separated from 24 after transformation to the corresponding pyrazoline derivative. The structures of 16 , the corresponding
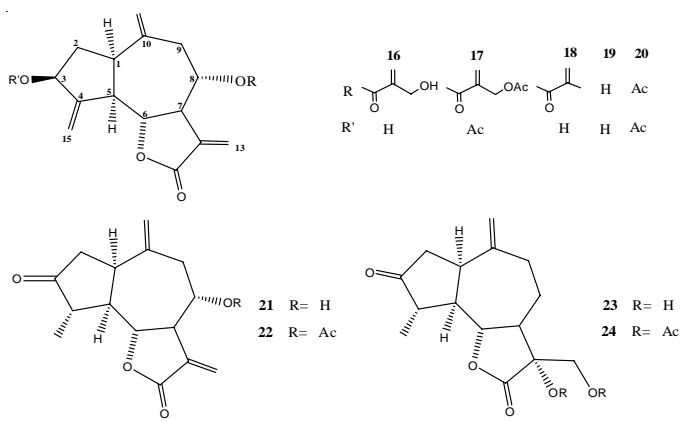

Fig. 4.Chemical structures of Sesquiterpene lactones from Centaurea behen L.16-24 
diacetate 17, 18, 19 and 21 were elucidated by their $\mathrm{H}^{1}$-NMR data ${ }^{17}$.

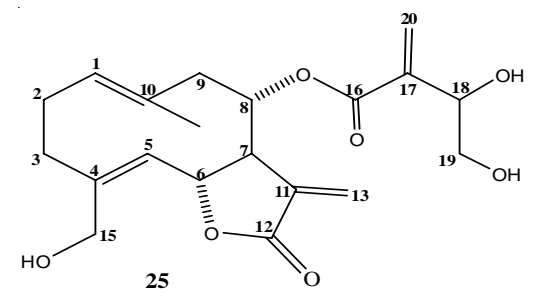

Fig. 5.Chemical structure of Sesquiterpene lactone from Centaurea brugueriana DC. 25.

Chemical Constituents of Centaurea brugueriana DC.

Cinicin a germacranolide has been isolated from chloroform extract of the aerial parts of Centaurea brugueriana DC. (Compositae) ${ }^{18}$.
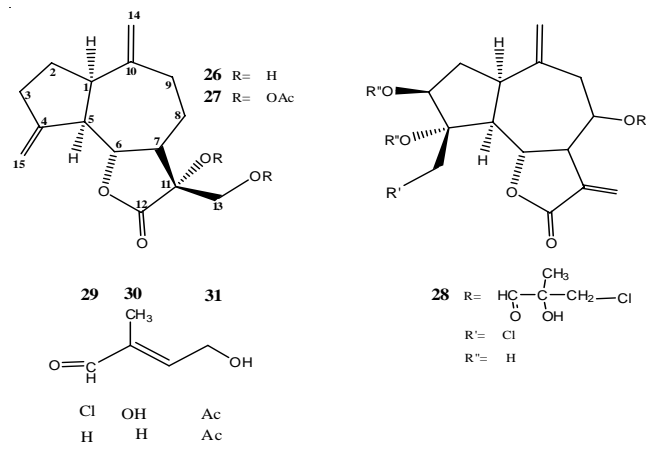

Fig. 6. Chemical structure of Sesquiterpene lactone from Centaurea imperialis Hausskn.ex Bornm. 26-31.

\section{Centaurea imperialis}

The aerial parts of Centaurea imperialis afforded three new guaianolides, 3-desoxysolstitialin A and two derivatives of centaurepensin ${ }^{19}$.

\section{Guaianolides from Centaurea kandavanensis Wagenitz.}

From the large genus Centaurea (Compositea) numerous different types of constituents, especially guaianolides, have been reported ${ }^{20}$. We now have investigated a species which grows on the mountains near Kandavan.

The polar fraction afforded two crystalline compounds, the guaianolides 32 and 34 . The molecular formula of 32 was $\mathrm{C}_{17} \mathrm{H}_{20} \mathrm{O}_{5}$ as followed from the mass spectrum. The $\mathrm{H}^{1}$-NMR spectrum showed the typical signals of methylene lactones. Furthermore the presence of two additional exomethylene groups, acetate and a hydroxyl group could be deduced from the spectrum which was in part close to that zaluzanin $C$ acetate ${ }^{21}$.

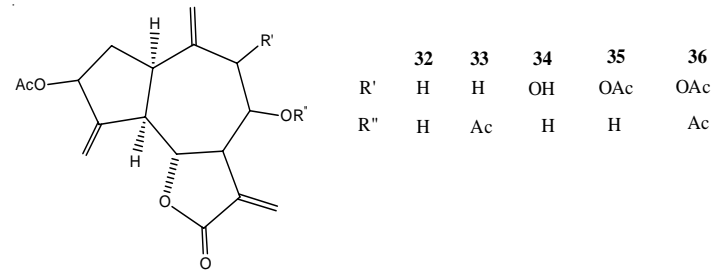

Fig. 7. Chemical structure of Sesquiterpene lactone from Centaurea kandavanensis Wagenitz. 32-36.

The more polar lactone 34, Molecular formula $\mathrm{C}_{17} \mathrm{H}_{20} \mathrm{O}_{6}$, obviously was the $9 \alpha$-hydroxy derivative of 32 . This investigation shows again that guaianolide derived from zaluzanin $\mathrm{C}$ may be characteristic for large parts of the genus Centaurea ${ }^{22}$.

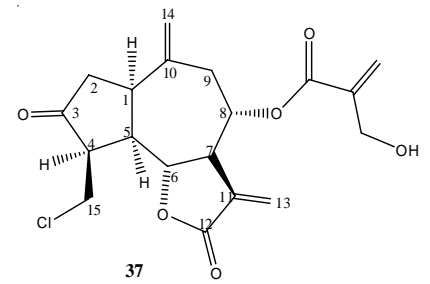

Fig. 8. Chemical structure of Sesquiterpene lactone from Aegopordon berarioides Boiss. 37.

A New Guaianolide from Aegopordon berarioides Boiss.

The aerial parts of $A$. berarioides afforded, in addition to lupeol, taraxasterol, sitosterol-3-Oglucoside and cynaropicrin and a new guaianolide, the structure of which was deduced by high-field $\mathrm{H}^{1}$-NMR spectroscopy. The plant materials were collected in west of Kerman, Iran ${ }^{23}$.

\section{Sesquiterpene Lactones and Eudesmane Derivatives from Onopordon carmanicum (Bornm.) Bornm.}

The aerial parts of Onopordon carmanicum (Bornm.) Bornm afforded in addition to Onopordopicrin and two related esters the epoxide of Onopordopicrin, a new elemane derivative, two eudesmanolides and two eudesmane derivatives which most likely are the precursors of the latter lactones. The structures were elucidated by highfield NMR spectroscopy ${ }^{24}$.

The genus Onopordon (Compositae, tribe Cynareae) is placed together with the large genera Cousinia, Saussurea and Jurinea in the subtribe Carduinae. Taxonomically this genus is closely 
related to Cousinia, while the position of Jurinea and Saussurea is uncertain ${ }^{25}$. So far from the genus Onopordon in addition to widespread compounds several $\mathrm{C}_{17}$-acetylenes ${ }^{26}$ and the germacranolide Onopordopicrin ${ }^{27,28,4,3}$ as well as closely related lactones ${ }^{4,3}$ have been reported.

Similar 15-hydroxyl germacranolides with an $8 \alpha$-acyloxy group have been isolated from Jurinea species. This type of sesquiterpene lactone seems to be characteristic for a group of genera in the Cynareae. They have been reported from Centaurea, Arctium and Cnicus species. However, lactones with the same substitution pattern with an additional hydroxyl group at $\mathrm{C}-14$ are reported from Dicoma species (tribe Mutisieae) ${ }^{29}$. This type is present also in some Jurinea species ${ }^{30}$. From Cousinia species so far no lactones are reported. We have studied now a further Onoportdon species O. carmanicum (Born.) Born.

The polar fractions of the extract of the aerial parts of $O$. carmanicum gave as the main constituents Onopordopicrin $(40)^{27}$ as well as a complex mixture of sesquiterpene lactones which could be separated by HPLC. In addition to the isobutyrate $1^{3}$ and the corresponding methacrylate $39^{3}$ the $4 \alpha, 5 \beta$-epoxide of Onopordopicrin (46), the epimeric aldehydes 41 and 42 , the epimeric methyl esters of the corresponding precursors 43 and 44 as well as the elemane 45 were isolated ${ }^{24}$.
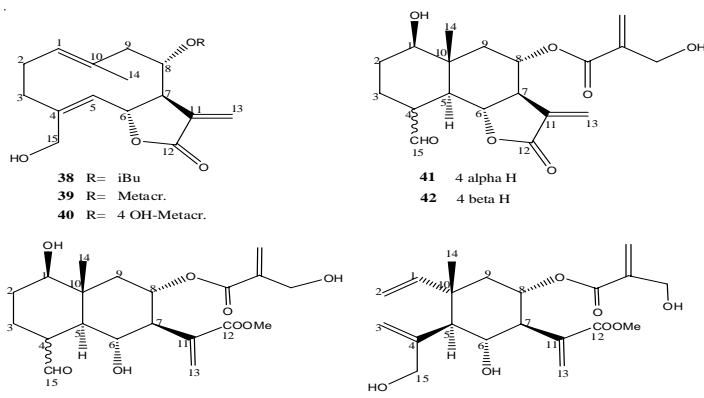

434 alpha $\mathrm{H}$

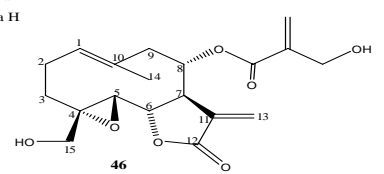

Fig. 9. Chemical structure of Sesquiterpene lactone from Onopordon carmanicum born.38-46.

\section{Sesquiterpene Lactones from Achillea micrantha} M.B.

The aerial parts of Achillea micrantha afforded the eudesmanolides santamain, reynosin, dihydrosantamarin, dihydroerynosin and the germacronolides artemorin, gallicine, dihydroparthenolide as well as a new one, dihydropartenolide bisepoxide 47 . The structures were elucidated by spectroscopy data.From the large genus Achillea (compositae-anthemideae) several sesquiterpene lactones were reported ${ }^{31}$. We now have studied Achillea micrantha M. B. Careful separation by thin layer and high pressure liquid chromatography of the polar fraction of the column chromatography of the extracted of the aerial parts afforded dihydroparthenolide ${ }^{32}$, santamarin ${ }^{33}$, dihydrosantamarin ${ }^{34}$, dihydroreynosine ${ }^{33}$, reynosin ${ }^{35}$, gallicin ${ }^{36}$, artemorin ${ }^{37}$ and a new lactones with molecular formula $\mathrm{C}_{15} \mathrm{H}_{20} \mathrm{O}_{4}{ }^{38}$

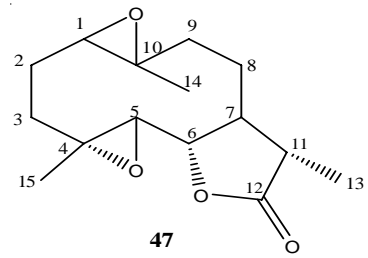

Fig. 10. Chemical structure of Sesquiterpene lactone from Achillea micrantha M.B. 47.

Germacranolides from Anvillea garcini (Burn.) DC

The aerial parts of Anvillea garcini (Burn.) DC afforded three germacranolides, two of which had not being isolated previously. The structers were elucidated by ${ }^{1} \mathrm{H}-\mathrm{NMR}$ spectroscopy. The configuration of 9 -acetoxy parthenolide at $\mathrm{C}-9$ has been revised ${ }^{39}$.

The small genus Anvillea garcini (tribe Inuleae, subtribe Inulina) is placed in the Inula group ${ }^{40}$. From A. garcini (Burn.) DC flavones ${ }^{41}$ and $9 \alpha$-hydroxyparthenolide $(48)^{42}$ were reported.
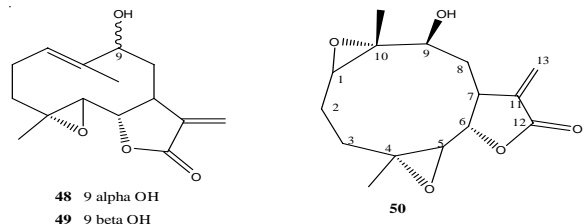

Fig. 11. Chemical structure of Sesquiterpene lactone from Anvillea garcini (Burn.)DC 48-50. 
An investigation of a sample collected in the South of Iran gave in addition to $9 \alpha$ hydroxyparthenolide (48), two further lactones, 49 (the epimer of 48) and 50 (the epoxide of 49). The structures were elucidated by high filed proton NMR spectroscopy ${ }^{39}$.

\section{Sesquiterpene Lactones from Jurinella moschus} (Halb)

The aerial parts of Jurinella moschus afforded the lignane arctigenin, four sesquiterpene lactones, the germacranolides salonitenolide and two new ones as well as a new elemanolide. The structures were elucidated by high filed proton-NMR spectroscopy ${ }^{43}$. The small genus Jurinella (compositeae Cynareae, Carduinae), which is distributed over SW Asia, has hitherto not been a subject for chemical study. The investigation of the aerial parts of Jurinella moschus (Halb.) Bobrov afforded salonitenolide (51) ${ }^{44}$ and arctigenin (55) ${ }^{45}$ as well as three new sesquiterpene lactones, the elemanolide 54, named 20-hydroxyelemajurinelloide ${ }^{43}$.
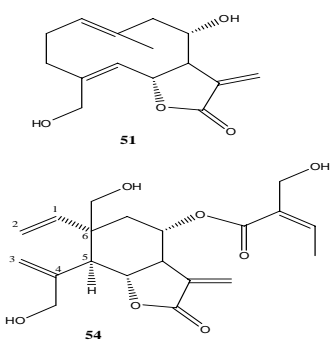
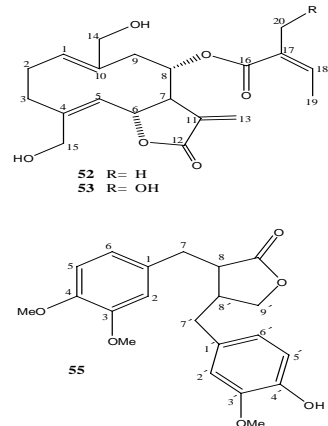

Fig. 12.Chemical structure of Sesquiterpene lactone from Jurinella moschus (Halb) 51-55.

The $\mathrm{H}^{1}$ - NMR spectra of 51 and 55 were identical with those of authentic material. As the NMR data of the latter have not been reported in the literature we have added then in the Experimental $^{43}$.

\section{Further Sesquiterpene Lactones from Genus Dittrichia}

The aerial parts of Dittrichia graveolenes afforded in addition to compounds isolated previously five new sesquiterpene lactones, two benzoic acid derivatives while $D$. viscosa gave two further derivatives of costic acid. The structures were elucidated by high filed NMR spectroscopy ${ }^{46}$.
From the small genus Dittrichia, previously a section of Inula, one species, D. viscosa (L.) Greuter, has been investigated chemically. In addition to costic acid derivatives ${ }^{47}, 48,49,50$, the aerial parts of this very widespread species gave sesquiterpene lactones ${ }^{48,49,50}$ as well as some flavonoids ${ }^{51}$.From the roots, in addition to a thymol derivative ${ }^{49}, 52$, several rare germacnolides were isolated ${ }^{52}$.<smiles>CCCCCCCC(C)CCCC(C)c1ccccc1C</smiles>
$\stackrel{56}{56} \underset{\mathrm{R}=\mathrm{H}}{\mathrm{H}=\mathrm{OH}}$

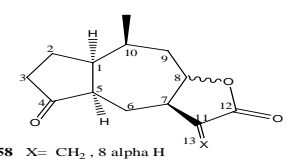
$58 \mathrm{X}=\mathrm{CH}_{2}, 8$ alpha $\mathrm{H}{ }^{13} \times$
$59 \mathrm{X}=$ alpha Me, H, 8 beta $\mathrm{H}$
$60 \mathrm{X}=$ beta Me, $\mathrm{H}, 8$ alpha $\mathrm{H}$

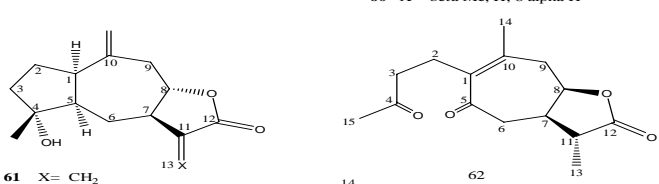
61 $\mathrm{X}=\mathrm{CH}_{2}$
$61 \mathrm{C}=$ alpha $\mathrm{Me}, \mathrm{H}$
61b $\mathrm{X}=$ alpha $\mathrm{Me}, \mathrm{H}, 1 \mathrm{ep}$<smiles>C=C1C=C(C)[C@]2(C)[C@@H](CC[C@@]2(C)C(=O)O)C1</smiles>

$\begin{array}{ll}\text { 63a } & \mathrm{X}=\mathrm{H}_{2} \\ \text { 63b } & \mathrm{X}=\mathrm{O}\end{array}$

63b $\mathrm{X}=\mathrm{O}$
$\mathbf{6 3} \mathrm{X}=$ alpha $\mathrm{OH}, \mathrm{H}$

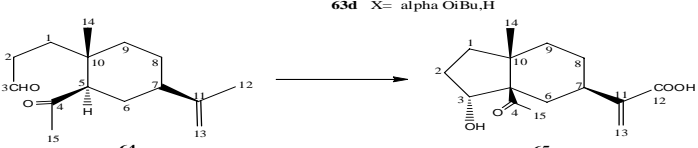

Fig. 13. Chemical structure of Sesquiterpene lactone from Genus Dittrichia 56-65.

From D.graveolens (Desf.)Greuter, grareolides ${ }^{53}$ and pseudoguaianolide without assignment of stereochemistry were reported ${ }^{54}$. We have now reinvestigated a sample from Iran. In addition to known compound, several new sesquiterpene lactones and two unusual benzoic acid derivatives were isolated. From Dittrichia tenerile (Canary Islands) similar lactones but also a new costic acid derivative and a rearranged sesquiterpene were isolated $56-65^{46}$.
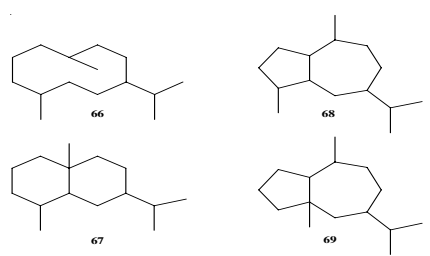

Fig. 14. The frame works Sesquiterpene lactone from Artemisia diffusa 66-69. 
Sesquiterpene Lactones from Artemisia diffusa Several reviews on the sesquiterpene lactones of the genus Artemisia have appeared in the literature ${ }^{20}$ which discuss the taxonomic conclusions to be derived from the distribution of sesquiterpene lactones within Artemisia species, the majority of these lactones exhibit one of the four frameworks represented below, i.e. germacrane 66, eudesmane 67, guaiane 68 and pseudoguaiane 69 .

Reports dealing with isolation and structure elucidation of sesquiterpene lactones have increased dramatically. Two reasons can be given for the strongly increasing interest in this group of natural products. First, sesquiterpene lactones have been successfully used as markers in biochemical systematic (chemotaxonomy) studies mainly in the Compositae. Secondly, a number of compounds received considerable attention due to varies biological activities.

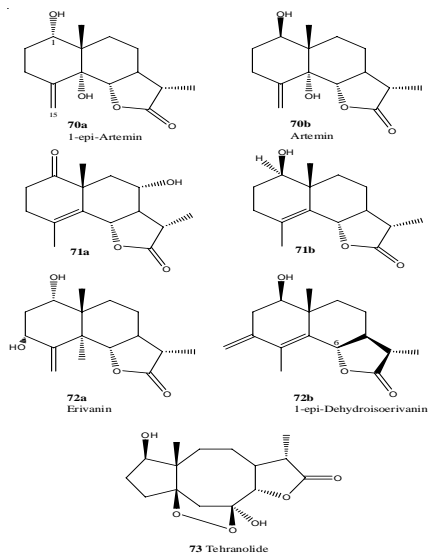

Fig. 15. Chemical structure of Sesquiterpene lactone from Artemisia diffusa 70a-73.

The genus Artemisia is not very uniform and the chemistry is somewhat diverse. However, most species contain sesquiterpene lactone, especially 11 , 13- dihydroderivatives.

The extract of the aerial parts of $A$. diffusa afforded several eudesmanolides (70a, 70b, 71a, 71b, 72a, 72b, 73) and a new type of sesquiterpene lactone with unusual carbon skeleton, an eightmember ring (Tehranolide) $(73)^{55}$.

Most likely this unusual carbon skeleton was formed by oxidative cleavage of the $\Delta 4$ bond of $71 \mathrm{~b}$ followed by an internal aldol condensation of the intermediate 5 affording the dihydroxy ketone
75. The latter then could be rearranged to the lactone 76 by attack of $\mathrm{HO}^{+}$followed by acetal formation to give the lactone 73 (Tehranolide).
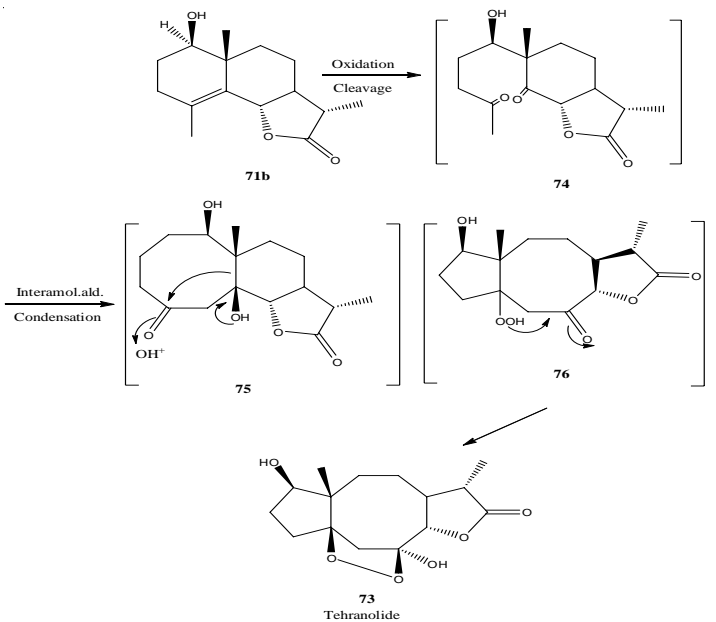

Fig. 16. Biosynthesis of Tehranolide

The extract of the aerial parts of $A$. diffusa collected in the Province of Khorasan (Iran) afforded, in addition to several eudesmanolides a new type of sesquiterpene lactone (Tehranolide) with an endoperoxide group that probably has the same effect as the antimalarial agent artemisinin.

We have already reported the antimalarial properties of the extract of the extract and the fraction which contains sesquiterpene lactones including Tehranolide of the same species (Artemisia diffusa) $)^{56,57,58}$.

Recently Artediffusin (Tehranolide) has been confirmed and considered as a new antimalarial agent ${ }^{59}$.

\section{Biological Activities}

Sesquiterpene lactones are one of the most prevalent and biologically significant classes of secondary metabolite present and hence have been subject to a number of studies. In addition, sesquiterpene lactones have anticarcinogenic, antiinflammatory capacity ${ }^{63}$. Asteraceous plants are in turn the most diverse and prolific plant family in the world.

To humans, lettuce and chicory (Lactuca sativa and Chicorium inty bus L.) represent the main dietary source of sesquiterpene lactones, on the basis of the levels of their global consumption. 
Casagrande ${ }^{61}$ indicates that $11 \%$ of Americans studied reach their targets for both fruit and vegetables, though $28 \%$ and $32 \%$ reached individual targets of two fruit per day and three vegetables per day respectively in 2002 whereas the latest study found only $16 \%$ of UK reach their 5 a day target ${ }^{62}$.

Additionally a range of Asteraceous plants are used to impart the bitterness of some alcoholic beverages. Other sources of sesquiterpenoids include spices for example star anise, and herbs, though consumption levels of these are understandably smaller. Traditional medicinal plants can also be a significant source for some populations, as sesquiterpenoids often represent the active ingredient ${ }^{63,64,65}$. These medicinal plants are often from the Compositae (Asteraceae) family of which "feverfew" (Tanacetum parthenium (L.) Sch. Bip.) Yarrow (Achillia spp.), and quinghaosu ( $A$. annua) in the treatment of malarial type ailments, are among the most commonly used both in historically and in current alternative treatments ${ }^{66}$.

Roman chamomile flower (Chamomillae romanae flos) is the inflorescence of Anthemis nobilis L. (sometimes known under the name Chamaemelum nobile (L.) All.). The plant grows wild in southern and western europe and also in North Africa. It is cultivated in several European countries, as well as in Egypt and in Argentina.<smiles>C=C1C(=O)O[C@@H](/C=C(\C)[C@@H](O)C/C=C\C)C[C@@H]1[C@H](CC)OC(=O)/C(C)=C/C</smiles>

Fig. 17. Chemical structure of nobilin from Anthemis nobile (L.) 77.

Roman chamomile flowers contain 0.6$2.4 \%$ volatile oil, the main components of which are esters, in particular the isobutyl ester, of angelic. Also present in the drug are sesquiterpene derivatives, e.g. the lactone nobilin 77 , which has a bitter taste, and flavonoids with a spasmolytic effect, e.g. apigenin 7-glucoside.
Roman chamomile flower- usually taken as a tea- is an herbal remedy for colic and several other complaints ${ }^{67}$.

Parthenolide is a sesquiterpene derivative which is contained in leaves of feverfew, Chrysanthemum parthenium Bernh. (Some times known as Tanacetum parthenium Sch. Bip.), an herbal remedy used for prophylaxis of migraine. This activity has been proved clinically. Parthenolide is an inhibitor for blood platelet aggregation. Release of 5-hydroxytryptamine (serotonin) accompanies platelet aggregation and has been linked to the onset of migraine ${ }^{67}$.

The $\alpha$-methylene butyrolactone function of parthenolide is a Michael acceptor of thiols. It has been suggested that this reaction is responsible for the inhibitory effect of the compound

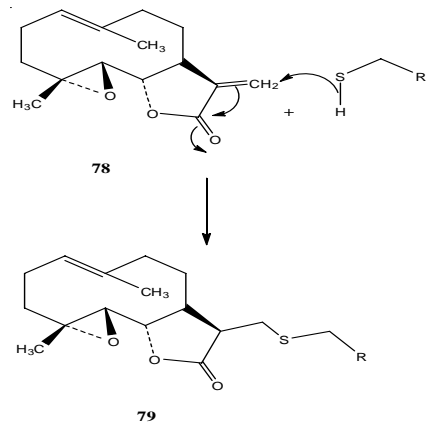

Fig. 18. The $\alpha$-methylene butyrolactone function of parthenolide is a Michael acceptor of thiols

on blood platelet aggregation. Secondly, the inhibitory effects are dose- and time- dependent, and thirdly, treatment of platelet with feverfew extracts or parthenolide causes a dramatic reduction in the number of acid- soluble thiolgroup's present ${ }^{67}$.On the other hand doubts have been raised as to the credibility of this explanation in the clinical situation as parthenolide entering the bloodstream would be rapidly "neutralized" by Michael addition of the thiol residue in glutathione, which is one of the body's main defenses against such compounds $(78,79)^{67}$.

\section{Antimalarial Activity Artemisinin and its derivatives}

In 1972, a group of Chinese researchers isolated a new anti-malarial drug (+) - artemisinin (1), a sesquiterpene lactone of the amorphene sub 
group of cadinene from the hexane extract of a traditional Chinese medicinal plant Artemisia annua (Asteracea)- a plant which has been used for the treatment of fever and malaria since ancient time ${ }^{68}$.

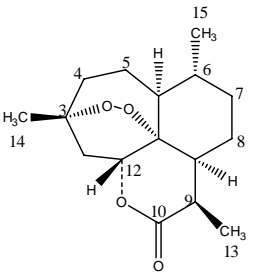

80a

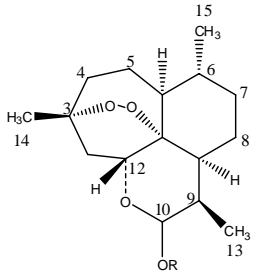

80b
Fig. 19. Chemical structure of Artemisinin and Dihydroartemisinin (R: H) $80 a-80 b$

Artemisinin is a sesquiterpene lactone containing an endoperoxide linkage in it. This highly oxygenated sesquiterpene lactone peroxide, unlike most other anti-malarials, lacks nitrogens containing heterocyclic ring systems and was found to be super plusmocidal and blood Schizontocidal agent to conventional anti-malarial drugs, such as chloroquine, quinine etc. against malaria strains, without obvious adverse effects in patients.

\section{Tehranolide as a new Antimalarial Candidate}

Since the discovery and the use of artemisinin and endoperoxide sesquiterpene lacton, particular attention has been directed to this class of compounds, we have investigated many Iranian Artemisia species.

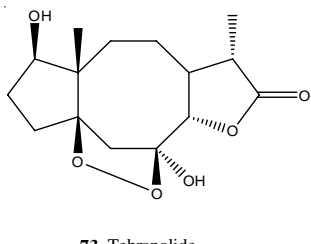

Fig. 20. Chemical structure of Tehranolide 73.
Artemisia aucheri 69, 70, 71, A. austriaca 72, A. biennis 73, $A$. campestris $73, A$. deserti $74, A$. diffusa 53, 56, 75, A. gypsacea 76, 77, A. haussknechtii 78, A. kermanensis78, A. kopetdaghensis 78, A. kulbadica 79, A. oliveriana $80, A$. persica $81, A$. santolina $77, A$. sieberi $82,83,84$, A. tschernieviana 73, A. ciniformis 85 , A. incana 85 , A. turanica86 and A. tournefortiana 71.

From all these species, we discovered an unusual sesquiterpene lactone with endoperoxide group, which we have named Tehranolide. The extract of the aerial parts of $A$. diffusa afforded several eudesmanolide and a new type of sesquiterpene lactone with unusual carbon skeleton, an eight member ring 59.

The anti-malarial activity was determined by using different concentrations including 10, 30, $50 \mathrm{mg} / \mathrm{ml}-1$ of Tehranolide were made in drug vehicle including distilled water, methanol, DMSO and applied for therapy. Percentage of parasitaemia was counted after 24, 48 and 72 h. after treatment for each concentration. Results indicated no effects of Iow concentration of Tehranolide on parasitaemia, however the concentrations of 10,30 and $50 \mathrm{mg} / \mathrm{ml}-1$ represented their anti-plasmodial activities. The cytotoxic effects of high concentration occurred by destroying both parasites and RBCs in culture medium. Inhibition concentration of $50 \%\left(\mathrm{IC}_{50}\right)$ on plasmodial survival was observed at concentration of $10 \mathrm{mg} / \mathrm{ml}-1$ after 48-72 h. of treatment. It is concluded that, Tehranolide seems to be a promising drug exhibiting good anti-malarial effects in this human malaria $P$. falciparum model in vitro. However, more research is required before Tehranolide can be used for malaria treatment in human cases 87.

\section{ACKNOWLEDGMENT}

The authors are very thankful to Miss. Mahdieh Ariaee Fard for typing the manuscript.

\section{REFERENCES}

1. Wedge, D.E.; Galindo, J.C.; Macías, F.A. Phytochemistry. 2000, 53, 747-757.

2. De Luque, A.P.; Galindo, J.C.G.; Macías, F.A.; Jorrín, J. Phytochemistry. 2000, 53, 45-50.

3. Rustaiyan, A.; Nazarians, L.; Bohlmann, F. Phytochemistry. 1979, 18, 883-884.

4. Rustaiyan, A.; Nazarians, L.; Bohlmann, F.
Phytochemistry. 1979, 18, 879-880.

5. Evstratova, R.I.; Rybalko, K.S.; Sheichenko, I. Chem. Nat. Compd. 1972, 8, 450-457.

6. Rustaiyan, A.; Niknejad, A.; Bohlmann, F.; Schuster, A. Phytochemistry. 1981, 20, 1154.

7. Evstratova, R.I.; Sheichenko, V.I.; Rybalko, K.S. Khim. Prir. Soedin. 1973, 9, 161. 
8. Evstratova, R.I.; Rybalko, K.S.; Rzazade, R.Y. Khim. Prir. Soedin. 1967, 3, 384.

9. Gonzales, G.A.J.; Bermejo Barrera, J.; Breton Funes, J.L.; Triana, J. Tetrahedron Lett.1972, 13, 2017-2020.

10. Rustaiyan, A.; Nazarians, L.; Bohlmann, F. Phytochemistry. 1981, 20, 1152.

11. Suchy, M.; Herout, V.; Sorm, F. Collect. Czech. Chem. Commun.1960, 25, 2777.

12. Gonzales, G.A.J.; Bermejo, J.; Cebrera, I.; Massanet, G.M.; Mansila, H.; Galindo, A. Phytochemistry. 1971, 17, 955-956.

13. Gonzales, A.G.; Bermejo, J.; Massanet, G.M. Perez, J. Ann. Quim. 1973, 69, 1333.

14. Corbela, A.P.; Garriboldi, P.; Jommi, G.; Samek, Z.; Holub, M.; Drozdz, B. Chem. Commun. 1972, 386.

15. Thiessen, W.E.; Hope, H. Acta Crystalloger. Sect. 1970, B 26, 554.

16. Rustaiyan, A.; Niknejad, A.; Zdero, C.; Bohlmann, F. Phytochemistry. 1981, 20, 2427-2429.

17. Rustaiyan, A.; Niknejad, A.; Aynehchi, Y. Planta Med.1982, 44, 185-186.

18. Rustaiyan, A.; Sharif, Z.; Tajarodi, A.; Ziesche, J.; Bohlmann, F. Planta Med.1984, 2, 193-194.

19. Seaman, F.C. Bot. Rev.1982, 48, 121-594.

20. Asakawa, Y.; Takemoto, T. Phytochemistry. 1979, 18, 285-288.

21. Rustaiyan, A.; Ardebili, Sh. Planta Med. 1984, 4, 363-364.

22. Izaddoost, M.; Dabiri, M.; Rustaiyan, A. Fitoterapia. 1985, 56, 275-277.

23. Rustaiyan, A.; Ahmadi, B.; Jakupovic, J.; Bohlmann, F. Phytochemistry. 1986, 25, 16591662.

24. Dittrich, M. in: The Biology and Chemistry of the Compositae, Heywood, V.H., Harborne, J.B. and Turner, B.L., Eds., London: Academic Press, 1977, 1010.

25. Bohlmann, F.; Burhardt, T.; Zdero, C. Naturally Occurring Acetylenes, London: Academic Press, 1973, 448.

26. García, B.; Skaltsa, H.; Navarro, F.ı.; Pedro, J.; Lazari, D. Phytochemistry. 1996, 41, 1113-1117.

27. Miski, M.; Meriçli, A.H.; Mabry, T.J. Phytochemistry. 1988, 27, 1417-1420.

28. Bohlmann, F.; Singh, P.; Jakupovic, J. Phytochemistry. 1982, 21, 2029-2033.

29. Fujimoto, Y.; Kinoshita, T.; Ikekawa, N.; Mungarulire, J. Phytochemistry. 1987, 26, 2593-
2595.

30. Trendafilova, A.; Todorova, M.; Mikhova, B.; Vitkova, A.; Duddeck, H. Phytochemistry. 2006, 67, 764-770.

31. Ogura, M.; Cordell, G.A.; Farnsworth, N.R. Phytochemistry. 1987, 17, 957-961.

32. Herz, W.; Lakshmikantham, M.V. Tetrahedron. 1965, 21, 1711-1715.

33. Shafizadeh, F.; Bhadane, N.R.; Morries, S.M.; Kelsey, R.G.; Khanna, S.N. Phytochemistry. 1971, 10, 2745.

34. Yoshioka, H.; Renold, W.; Fischer, N.H.; Higo, A.; Mabry, T.J. Phytochemistry. 1970, 9, 823-832.

35. Gonzales, A.G.; Bermejo, J.; Mansilla, H.; Massanet, G.M.; Cabrera, I.; Amarao, J.M.; Galindo, A. Phytochemistry.1977, 16, 1836-1837.

36. Kelsey, R.G.; Shafizadeh, F. Phytochemistry. 1979, 18, 1591-1611.

37. Rustaiyan, A.; Sharif, Z.; Tajarodi, A.; Sadjadi, A.S. phytochemistry. 1987, 26, 2856-2857.

38. Rustaiyan, A.; Dabiri, M.; Jakupovic, J. Phytochemistry. 1986, 25, 1229-1230.

39. Merxmuller, H.; Leins, P.; Roessler, H. in: The Biology and Chemistry of the Compositae, Heywood, V.H.; Harborne, J.B.; Turner, B.L. Eds., London: Academic Press, 1977, 590.

40. Ulubelen, A.; Mabry, T.J.; Aynekdin, Y. J. Nat. Prod.1979, 42, 624.

41. Tyson, R.L.; Chang, C.J.; McLaughlin, J.L.; Aynehchi, Y.; Cassady. J.M. Experientia. 1981, 37, 441.

42. Rustaiyan, A.; Ganji, M.T.; Phytochemistry. 1987, 26, 2857-2859.

43. Zdero, C.; Bohlmann, F. Phytochemistry. 1990, 29, 183-187.

44. Haworth, R.D.; Kelly, W. J. Chem. Soc.1937, 384.

45. Rustaiyan, A.; Jakupovic, J.; Chau-Thi, T.V.; Bohlmann, F.; Sadjadi, A. Phytochemistry. 1987, 26, 2603-2606.

46. Barbetti, P.; Chiappini, I.; Fardella, G.; Manghini, A. Planta Med. 1985, 51, 471.

47. Ceccherelli, P.; Curini, M.; Marcotullio, M.; Manghini, A. Phytochemistry. 1985, 24, 29872989.

48. Doskotch, R.W.; Wilton, J.H.; Harraz, F.M.; Fairchild, E.H.; Huang, C.T.; El-Feraly, F.S. J. Nat. Prod.1983, 46, 923-929.

49. Daniewski, W.H.; Kroszeynski, W.; Bloszyk, E.; Drozdz, D.; Nawrot, J.; Rychlewska, V.; Budesinsky, M.; Holob, M. Collect. Czech. 
Chem. Commun.1986, 51, 1710-1721.

50. Grande, M.; Picra, F.; Cuenca, A.; Torres, P.; Bellido, I.S. Planta Med.1985, 51, 414-419.

51. Bohlmann, F.; Gupta, R.K. Phytochemistry. 1982, 21, 1443-1445.

52. Wang, G.W.; Qin, J.J.; Cheng, X.R.; Shen, W.H.; Shan, L.; Jin, H,Z.; Zhang, W.D. Expert Opin. Investig. Drugs. 2014, 23, 317-345.

53. Chiappini, I.; Fardella, G. Fitoterapia. 1980, 51, 161.

54. Rustaiyan, A.; Sigari, H.; Jakopuvic, J.; Grenz, M. Phytochemistry. 1989, 28, 2723-2725.

55. Rustaiyan, A.; Nahrevanian, H.; Kazemi, M. Pharmacogn. Mag. 2009, 4, 1-7.

56. Rustaiyan, A.; Nahrevanian, H.; Kazemi, M. Proc. of BIT's 5th Anniversary Cong. of International Drug Discovery Science and Technology (IDDBST), Shanghai, 2007.

57. Rustaiyan, A.; Nahrevavian, H.; Kazemi, M. In: 57th International Congress and Annual Meeting of Society for Medicinal Plant and Natural Product Research, Geneva, 2009, 16-20.

58. Rustaiyan, A.; Nahrevanian, H.; Kazemi, M. Asian J. Chem.2011, 23, 4810-4814.

59. Merfort, I. CurrDrug Targets. 2011, 12, 1560-1573.

60. Casagrande, S.S.; Wang, Y.; Anderson, C.; Gary, T.L. Am. J. Prev. Med.2007, 32, 257-263.

61. Rogers, S.; Pryer, J.A. Public Health Nutr. 2012, 15, 1240-1247.

62. Canales, M.; Hernández, T.; Caballero, J.; de Vivar, A.R.; Avila, G.; Duran, A.; Lira, R. J. Ethnopharmacol.2005, 97, 429-439.

63. Bork, P.M.; Schmitz, M.L.; Kuhnt, M.; Escher, C.; Heinrich, M. FEBS Lett.1997, 402, 85-90.

64. Lyß, G.; Knorre, A.; Schmidt, T.J.;Pahl, H.L.; Merfort, I.; J. Biol. Chem., 1998, 273, 33508-33516.

65. Heinrich, M.; Robles, M.; West, J.E.; Ortiz de Montellano, B.R.; Rodriguez, E. Annu. Rev. Pharmacol. Toxicol.1998, 38, 539-565.

66. Samuelsson G., and Bohlin L., in Drugs of Natural Origin. in 6th Ed. A Treatise of Pharmacognosy, Stockholm, 2009.

67. Little, D.B.; Croteau, R.B. Arch. Biochem. Biophys., 2002, 402, 120-135.

68. Khorsand Mohammadpoor, S.; Yari, M.; Rustaiyan, A.; Masoudi, S. J. Essent. Oil Res.2002, 14, 122-123.

69. Wollenweber, E.; Favre-Bonvin, J.; Waton, H.; Hauteville, M.; Rustaiyan, A. Phytochemistry. 1992, 11, 105-107.
70. Rustaiyan, A.; Bamonieri, A.; Raffatrad, M.; Jakupovic, J.; Bohlmannt, F. Phytochemistry. 1987, 26, 2307-2310.

71. Rustaiyan, A.; Faridchehr, A. Res. Rev. J. Bot. Sci.2014, 3, 1-9.

72. Nematollahi, F.; Rustaiyan, A.; Larijani, K.; Nadimi, M. J. Essent. Oil Res.2006, 18, 339-341.

73. Kazemi, M.; Dakhili, M.; Rustaiyan, A.; Larijani, K.; Ahmadi, M.A.; Mozaffarian, V. Pharmacogn. Res. 2009, 2, 120-124.

74. Rustaiyan, A.; Komeilizadeh, H.; Masoudi, S.; Monfared, A.; Yari, M.; Kardar, M.; Shahgholi A. J. Sci. Islamic Repub. Iran. 2000, 11, 213-215.

75. Khazraei- Alizade, Kh.;Rustaiyan. A. J. Essent. Oil Res.2001, 14, 185-186.

76. Rustaiyan, A.; Zare, K.; Ganji, M.T.; Sadri, H.A. Phytochemistry. 1989, 28, 1535-1536.

77. Rustaiyan, A.; Balalaei, S.; Mohammadi, F.; Masoudi, S.; Yari, M. J. Essent. Oil Res.2000, 12, 330-332.

78. Rustaiyan, A.; Tabatabaei-Anaraki, M.; Kazemi, M.; Masoudi, S.; Makipour, P. J. Essent. Oil Res. 2009, 21, 410-413.

79. Aghajani, Z.; Kazemi, M.; Dakhili, M.; Rustaiyan A.; Nat. Prod. Commun.2009, 4, 1261.

80. Sanz, J.F.; Rustaiyan, A.; Alberto Marco, J. Phytochemistry. 1990, 29, 2919-2921.

81. Rustaiyan, A.; Ameri, A.; Mirjalili, B.F.; MazloumArdakani, M.; HakimiMaybody, M.; Bamoniri, A. Journal of Sciences (Islamic Azad University). 2003, 13, 1074-1078.

82. Weyerstahl, P.; Schneider, S.; Marschall, H.; Rustaiyan A. Eur. J. Org. Chem.1992, 2, 111 116.

83. Weyerstahl, P.; Schneider, S.; Marschall, H.; Rustaiyan, A. Flavour Fragrance J.1993, 8, 139-145.

84. Alberto Marco, J.; Sanz-Cervera, J.F.; Sancenon, F.; Jakupovic, J.; Rustaiyan, A.; Mohamadi, F. Phytochemistry. 1993, 35, 1061-1065.

85. Rustaiyan, A.; Masoudi, S.; Kazemi, M. J. Essent. Oil Res.2007, 19, 548-551.

86. Firouznia, A.; Akbari, MT.; Rustaiyan, A.; Masoudi, S.; Bigdeli, M.; Tabatabaei-Anaraki, M. J. Essent. Oil. Bear. PI.2007, 10, 88-993.

87. Rustaiyan, A.;Nahrevanian, H.;Zamani, Z.;Taherkhani, M.;Iravani, A. Res. J. Parasitol. 2015, 10, 73-78. 